\title{
In vitro biological activities of silver nanoparticles synthesized from Scedosporium sp. isolated from soil
}

\author{
Rajeeva Lochana Panchangam¹, Ravi Theaj Prakash Upputuri ${ }^{\oplus 2 *}$
}

\author{
${ }^{1}$ School of Bio Sciences and Technology, VIT University, Vellore, Tamil Nadu, India, ${ }^{2} P G$ Department of Bioscience, CMR \\ Institute of Management Studies, Bangalore, Karnataka, India
}

\begin{abstract}
One of the important fields in nanotechnology is the development of an environment friendly method for the synthesis of nanoparticles. Many approaches show that microorganisms are the most reliable tools for biosynthesis of nanoparticles compared to physical and chemical methods. In our study, fungi have been exploited for extracellular production of metal nanoparticles. It was observed that in Scedosporium, silver ions are reduced to silver nanoparticles, which was confirmed by UV-visible spectrophotometry and AFM. Optimization studies showed that as the concentration of $\mathrm{AgNO}_{3}$ used for synthesis increased, particles' size also increased. Size of the particles at different concentrations of $\mathrm{AgNO}_{3}$ was observed to be $79-107 \mathrm{~nm}$ with particles being ellipsoidal to spherical in shape. Silver nanoparticles synthesized from $2.0 \mathrm{mM}$ silver nitrate, showed maximum antimicrobial activity compared to all antibiotics tested including synergistic effects. In vitro cytotoxicity of silver nanoparticles against MCF 7 and PC 3 showed that as the concentration of silver nanoparticles increased, a decrease in the percentage cell viability was observed with $\mathrm{IC}_{50}$ values being 60.09 and $57.43 \mu \mathrm{g} / \mathrm{ml}$ respectively. Therefore, through this study, it could be said that extracellular synthesis of silver nanoparticles from Scedosporium was simple, ecofriendly, proving excellent antimicrobial and anticancer agents.
\end{abstract}

Keywords: Atomic force microscopy. In vitro cytotoxicity. Scedosporium sp. Silver nanoparticles. UV-visible spectroscopy.

\section{INTRODUCTION}

Nanoparticles are considered as fundamental building blocks of nanotechnology. Synthesis of nanoparticles is thus a major component of research in nanoscience (Vahabi, Mansoori, Karimi, 2011). Different types of nanoparticles are being synthesized in a number of ways, including the physical and chemical methods which pose a few disadvantages which are expensive, labor intensive, and are potentially hazardous to the environment and living organisms. Thereby, great interest is being created in researchers for the development of environmentally friendly method for the synthesis of nanoparticles. Nanoparticles synthesized from different fungal species have been reviewed by Siddiqi and Husen (2016). The antimicrobial potential of silver nanoparticles synthesized form different fungi has been explored by determining the size of the inhibition zone. A similar

\footnotetext{
*Correspondence: R. T. P. Upputuri. PG Department of Bioscience, CMR Institute of Management Studies, 560043 - Bangalore, Karnataka, India. E-mail: theaj_ravi@yahoo.com
}

review was reported by Keat et al. (2015), which also dealt with the biosynthesis of silver nanoparticles. Several methods followed for the synthesis has been elaborated, determining its antimicrobial activity, followed by several applications of silver nanoparticles. Silver nanoparticles, a major type of nanoparticles are widely used as an antiseptic agent due to its low toxicity against mammalian tissues (Sunderamoothi et al., 2009). These particles are known to be effective antimicrobial agents against a wide range of pathogenic microorganisms (Vigneshwaran et al., 2007). They have also been used in anti bacterial clothing, as coating for medical devices, and for burn ointments due to their mutation resistant anti microbial activity (Mohammadian, Shojaosadati, Rezaee, 2007). Silver nanoparticles are widely used in the fields of biolabelling, biosensors, and filters (Bhainsa, D'Souza, 2006). Apart from these, they are used in spectrally selected coatings for solar energybsorption, as optical receptors, as intercalation agents for electrical batteries, and also as catalysts in chemical reactions (Kalimuthu et al., 2008). The application of silver nanoparticles 
synthesized from Candida albicans isolated from dental caries has been reported by Saminathan (2015). The nanoparticles were observed to show potent antimicrobial activity against several multidrug resistant human pathogens. Biological syntheses have been developed as an alternative for physical and chemical synthesis, which are cost-effective and environmentally friendly (Sadowski et al., 2008). Many organisms, unicellular and multicellular have been used for the production of nanoparticles either intracellularly or extracellularly (Varshney et al., 2009). Organisms such as bacteria, algae, fungi and yeast have been exploited for the production of silver nanoparticles (Gajbhiye et al., 2009). The use of fungi has said to be more advantageous than bacteria and yeast. Some of the advantages include tolerance towards metals, uptake of metals intracellularly and maximum binding capacity (Dias et al., 2002). The production of fungi is also easy, thus producing large biomass for the synthesis of nanoparticles (Chen, Lin, Ma, 2003). Of the methods followed for the biosynthesis of nanoparticles, extracellular method is widely carried out. Intracellular synthesis allows the better control of size and shape, but harvesting the product and recovery are cumbersome and expensive. In case of extracellular synthesis, the enzyme nitrate reductase which is responsible for the production of silver nanoparticles is released into the medium where the $\mathrm{Ag}^{+}$ions are reduced to silver nanoparticles (Fayaz et al., 2010). Thus, the extracellular approach is the most effectively adapted method for the biosynthesis of silver nanoparticles from fungi.

The aim of this study was to green synthesize (biological synthesis) silver nanoparticles and to assess its cytotoxic ability on cancer cells. Therefore, this study presents the biological synthesis of silver nanoparticles from the fungus, Scedosporium, and the formation of nanoparticles was monitored through spectroscopic and microscopic characterization, followed by in vitro cytotoxicity study.

\section{MATERIAL AND METHODS}

\section{Biomass production}

For the production of fungal biomass, the culturing was carried out in liquid broth composed of $\mathrm{KH}_{2} \mathrm{PO}_{4}$ $(7.0 \mathrm{~g} / \mathrm{L}), \mathrm{K}_{2} \mathrm{HPO}_{4}(2.0 \mathrm{~g} / \mathrm{L}), \mathrm{MgSO}_{4} .7 \mathrm{H}_{2} \mathrm{O}(0.1 \mathrm{~g} / \mathrm{L})$, $\left(\mathrm{NH}_{4}\right)_{2} \mathrm{SO}_{4}(1.0 \mathrm{~g} / \mathrm{L})$ yeast extract, $(0.6 \mathrm{~g} / \mathrm{L})$ and glucose $(10 \mathrm{~g} / \mathrm{L})$ aerobically. The flask was incubated for about 11 days at a temperature of $29^{\circ} \mathrm{C}$. After incubation, the biomass produced was then harvested. This was then subjected by immense washing with Milli Q water.

\section{Synthesis of silver nanoparticles}

About $10 \mathrm{~g}$ of the biomass, after washing was inoculated into $100 \mathrm{~mL}$ Milli Q water. This was incubated for about $72 \mathrm{~h}$ at $29^{\circ} \mathrm{C}$. The biomass, after incubation was filtered using Whatmann No. 1 filter paper. The $\mathrm{pH}$ of the filtrate was observed to be 6.79 . To $100 \mathrm{~mL}$ of filtrate, silver nitrate was added at a concentration of $1 \mathrm{mM}$. The reaction was carried out in dark. A control was maintained along with the test sample, where it contained only the cell filtrate without silver nitrate. The formation of silver nanoparticles was monitored at a time interval of $2 \mathrm{~h}$ using a UV-visible Spectrophotometer, where wavelength scan was carried out from 200-600 nm.

\section{Optimization of synthesis of nanoparticles}

The cell filtrate containing the silver nanoparticles were further studied. The influence of substrate on the formation of silver nanoparticles was studied by changing the substrate concentration $(0.5,1.0,1.5$, $2.0 \mathrm{mM})$ at different time intervals. The absorbance was measured at wavelength of $430 \mathrm{~nm}$ using a UV- visible spectrophotometer.

\section{Characterization of silver nanoparticles}

The cell filtrate having the silver nanoparticles were characterized using Atomic Force Microscopy (AFM) to determine the size and shape of nanoparticles synthesized at various concentrations of $\mathrm{AgNO}_{3}$. The morphology of the synthesized nanoparticles was studied by AFM and was carried out to determine the particle height and volume. The sample analysis was carried out by preparing a smear with the pellet obtained from the filtrate containing the nanoparticles. This was then subjected to analysis through AFM.

\section{Antimicrobial activity}

The synergistic effect of antibiotics was studied using gram positive bacteria for the synthesized nanoparticles. Standard antibiotic discs were used. Standard antibiotics and antibiotics along with different concentrations of AgNPs $(0.5,1.0,1.5$ and $2.0 \mathrm{mM})$ were plated onto the Muller-Hinton agar plates. Overnight cultures of the test samples were used and incubated at $37^{\circ} \mathrm{C}$ for about $24 \mathrm{hrs}$. The zone of inhibition was measured.

\section{In vitro cytotoxicity studies}

The in vitro cytotoxicity studies of AgNPs were 
studied through MTT assay. Briefly, the cancer cells (MCF 7 and PC3, procured from National Center for Cell Science (NCCS), Pune, India) were cultured in DMEM and RPMI medium respectively containing $10 \%$ FBS in a culture flask at $37^{\circ} \mathrm{C}$ and $5 \%$ carbon dioxide. On reaching confluency, the cells were seeded in a 96 well plate at a cell concentration of approximately $5 \times 10^{3}$ cells/well and incubated for $24 \mathrm{~h}$. After incubation, the medium was removed and washed with PBS. To the control plates, serum free media was added and to the experimental plates, different concentrations of AgNPs were added $(12.5,25,50,75$ and $100 \mu \mathrm{g} / \mathrm{mL})$. After $24 \mathrm{~h}$ of incubation, the medium was removed and the cells were washed twice with PBS to remove any traces of drug and fresh medium was added. To each well, $5 \mu \mathrm{L}$ of MTT solution was added having a concentration of $10 \mathrm{mg} / \mathrm{mL}$ and further incubated for $4 \mathrm{~h}$. The medium was removed and the cells were dissolved in $100 \mu \mathrm{L}$ DMSO. The absorbance was measured at $570 \mathrm{~nm}$ in an ELISA micro plate reader. The data are shown as percentage viable cells of the test group in comparison with the control group.

\section{Statistical analysis}

All experiments were carried out in triplicates and the results are expressed as mean \pm S.D, with $p=0.05$.

\section{RESULTS}

The extracellular synthesis of silver nanoparticles from the fungus, Scedosporium, which was followed in this study and the flasks containing the filtrate in the presence and absence of substrate that taken as a control were presented in the Figure 1. As observed visually, the color of the filtrate was changed remarkably with increasing concentration of $\mathrm{AgNO}_{3}$, indicating the formation of silver nanoparticles. For further confirmation of this finding, UV- Visible spectral analysis was recorded between $200-600 \mathrm{~nm}$ at a regular time intervals, and an increase in spectra with a peak around $420-430 \mathrm{~nm}$ might be responsible for the production of silver nanoparticles due to its strong surface Plasmon resonance (Figure 2).

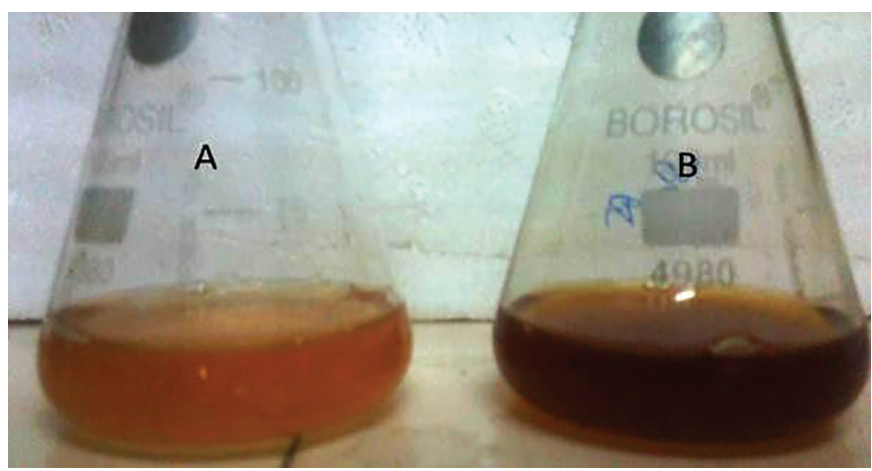

FIGURE 1 - Flasks showing only the cell filtrate (A) and cell filtrate with $\mathrm{AgNO}_{3}$ (B). Change in color in flask B shows the formation of silver nanoparticles.

Remarkably, it was clearly demonstrated that the production of nano-particles increased with increasing concentration of $\mathrm{AgNO}_{3}$, and the maximum amount was found to be produced at $2 \mathrm{mM}$ concentration (Figures 3 and 4). The size of the produced silver nano-particles as determined by AFM and same as color intensity the highest size of the nanoparticles was observed to be $107 \mathrm{~nm}$ at $2 \mathrm{mM}$ concentration, the maximum concentration used for analysis (Figure 5).

A study was carried out to determine the antibacterial activity of the silver nanoparticles synthesized extracellularly. The zone of inhibition of the antibiotics and the antibiotics along with the nanoparticles were measured. The results pertaining to the different concentrations of $\mathrm{AgNO}_{3}$ with the standard antibiotics are tabulated as in

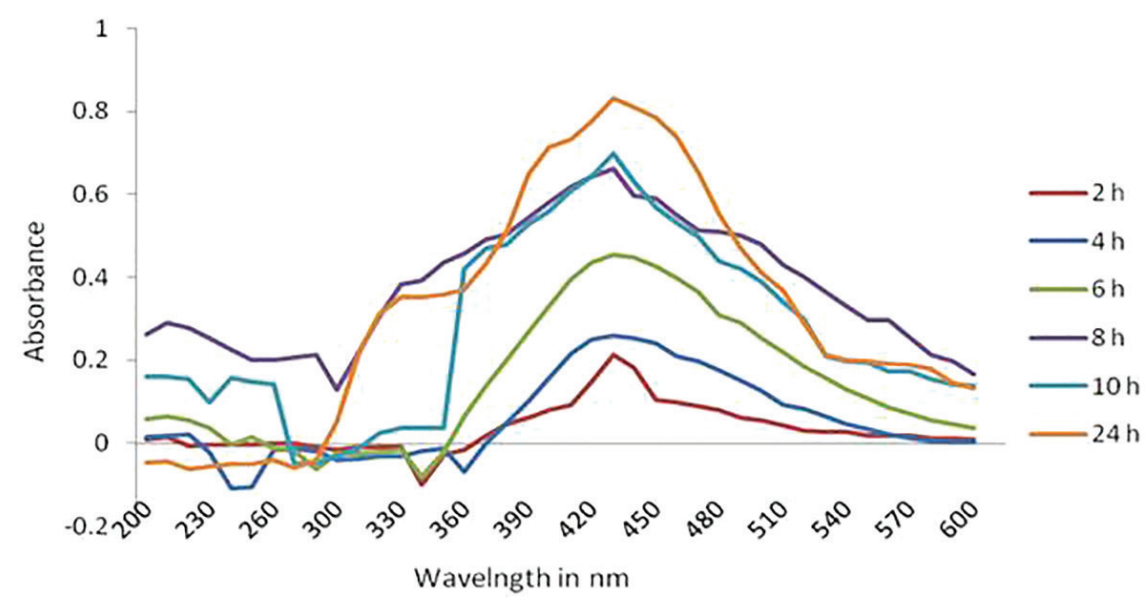

FIGURE 2 - UV spectrophotometric measurements at 2, 4, 6, 8, 10 and 24 h of incubation of cell filtrate with $\mathrm{AgNO}_{3}$. 


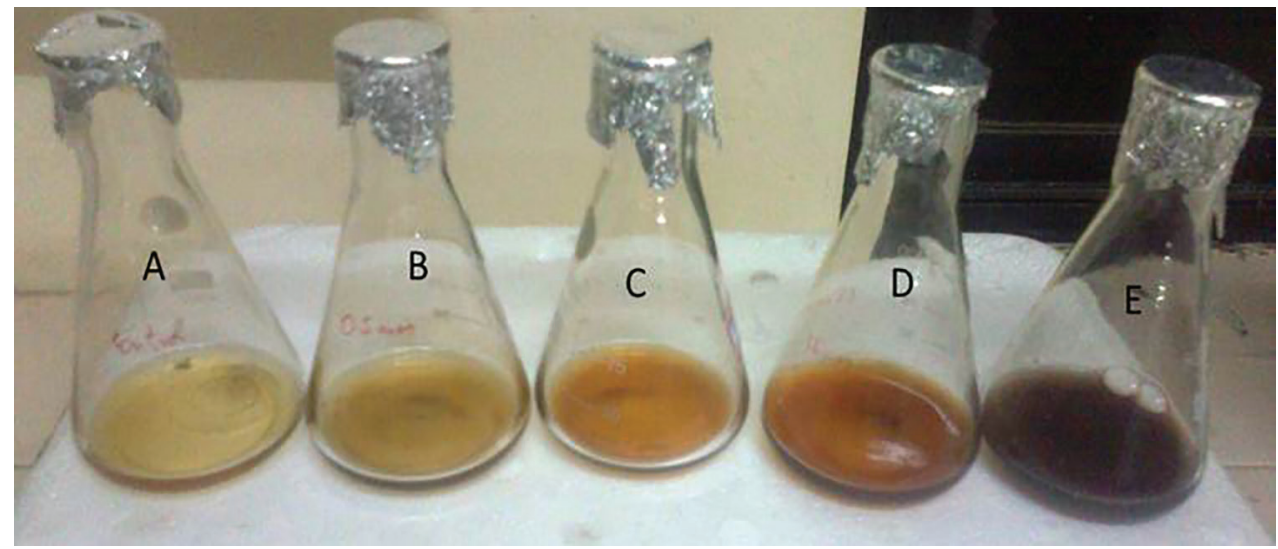

FIGURE 3 - Flasks showing cell filtrate with varying substrate concentration with control (A), $0.5 \mathrm{mMAgNO}_{3}(\mathrm{~B}), 1 \mathrm{mMAgNO} \mathrm{mM}_{3}(\mathrm{C})$, $1.5 \mathrm{mM} \mathrm{AgNO}_{3}(\mathrm{D})$ and $2 \mathrm{mM} \mathrm{AgNO}_{3}(\mathrm{E})$.

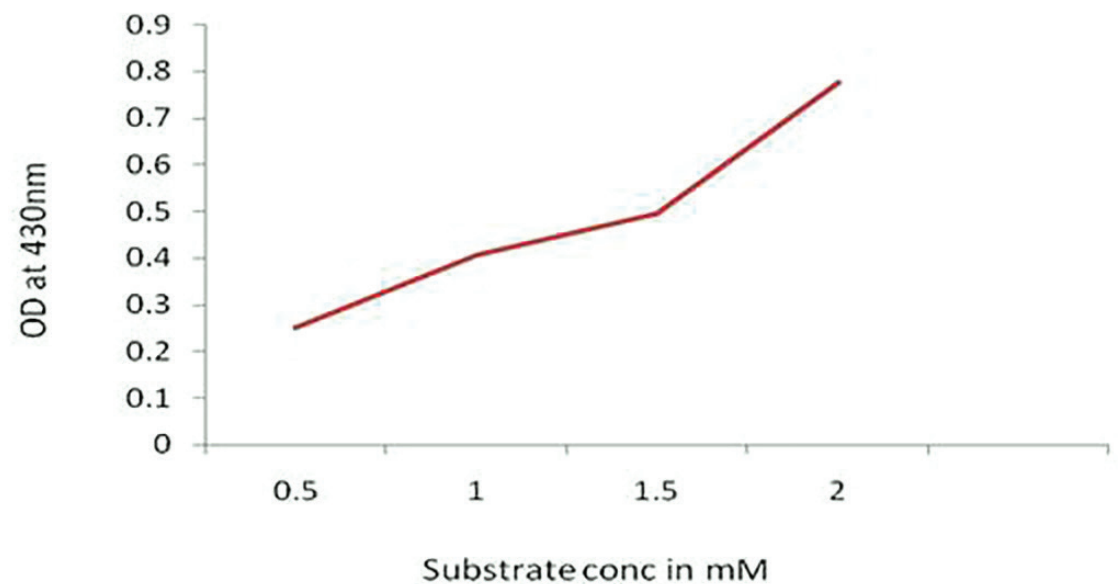

FIGURE 4 - Effect of substrate concentration on $\mathrm{AgNO}_{3}$ measured at $430 \mathrm{~nm}$ in a UV-vis sepectrophotometer.
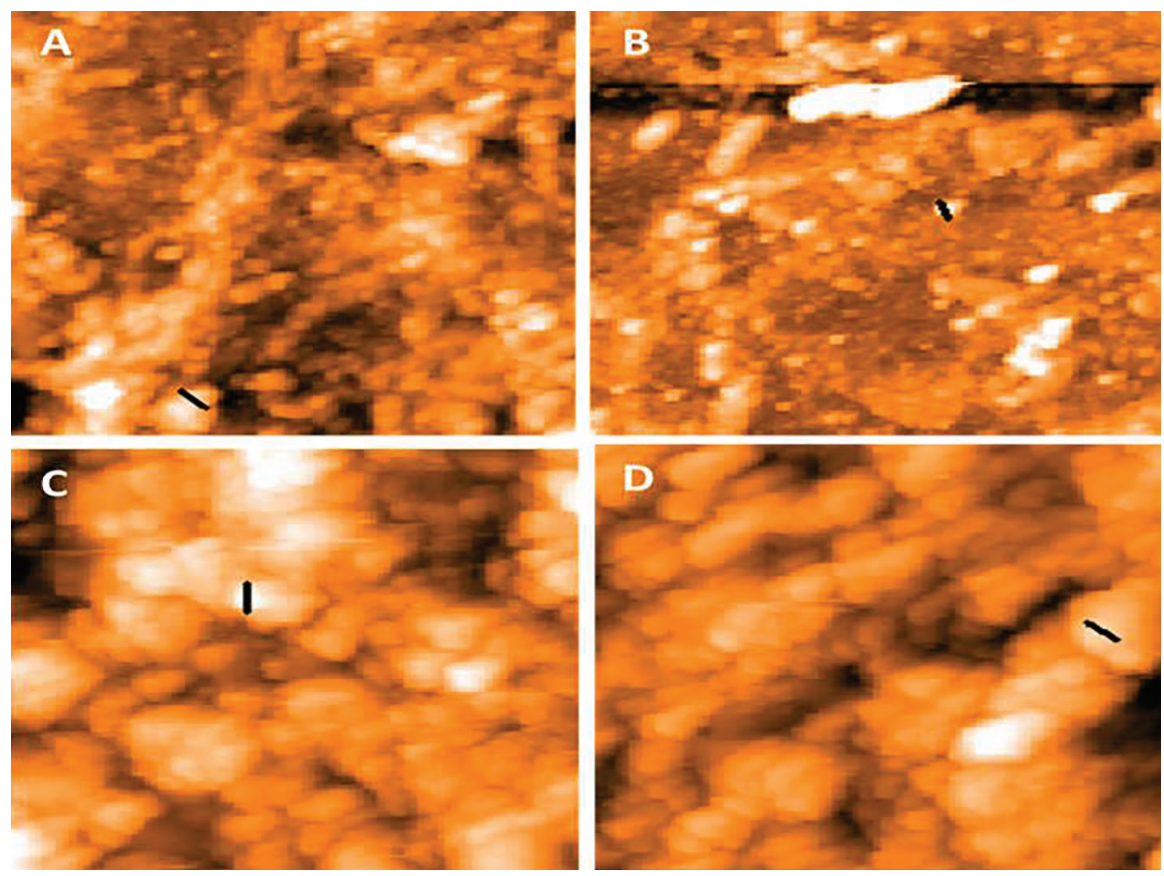

FIGURE 5 - Size of nanoparticles at different concentrations of $\mathrm{AgNO}_{3}$. AgNPs of size $79 \mathrm{~nm}$ at a concentration of $0.5 \mathrm{mM}$ (A), $88 \mathrm{~nm}$ at a concentration of $1 \mathrm{mM}(\mathrm{B}), 102 \mathrm{~nm}$ at a concentration of $1.5 \mathrm{mM}(\mathrm{C})$ and $107 \mathrm{~nm}$ at a concentration of $2 \mathrm{mM}(\mathrm{D})$. 
Table I (Figure 6). The zone of inhibition for different antibiotics at varying concentrations of $\mathrm{AgNO}_{3}$ against the gram positive bacteria was determined. Bacitracin was shown to have the maximum zone of inhibition against the test organism at all concentrations of $\mathrm{AgNO}_{3}$, followed by activity of vancomycin. The percentage of fold increase of antibiotics and the synergistic effect of antibiotics with AgNPs were calculated and plotted as in Figure 7.

In vitro cytotoxicity studies of different concentrations of AgNPs against MCF 7 and PC 3 showed a concentration dependent decrease in the cell viability. It was observed that as the concentration of AgNPs increased, a decrease in the percentage viable cells was observed (Figure 8). Similar results were observed for both, MCF 7 and PC 3 . The $\mathrm{IC}_{50}$ values were observed to be 60.09 and $57.43 \mu \mathrm{g} / \mathrm{ml}$ for MCF 7 and PC 3 respectively.

\section{DISCUSSION}

The extracellular synthesis of silver nanoparticle from the fungus, Scedosporium was carried out in this study. Figure 1 shows the two flasks containing the cell filtrate of Scedosporium with $\mathrm{AgNO}_{3}$ and without the silver ions. It was observed visually that there was a change in colour from pale yellow to dark yellowish brown after about $24 \mathrm{hrs}$ of incubation. The formation of yellowish brown colour serves as an indication for the formation of colloidal nanoparticles. The colour development was observed due to the excitation of surface plasmon vibrations in the silver nanoparticles (Ahmad et al., 2003; Duran et al., 2005; Kholoud et al., 2010). Thus, the production of silver nanoparticles is characterized by intense brown colour. It was also observed that as the

TABLE I - Zone of inhibition for different antibiotics (ampicillin, vancomycin, and bacitracin) against Gram positive bacteria (Staphylococcus aureus)

\begin{tabular}{|c|c|c|c|c|c|}
\hline \multicolumn{6}{|c|}{ Ampicillin $(10 \mu \mathrm{g} /$ disc $)$} \\
\hline & Amp (zone in mm) & $\begin{array}{c}\mathrm{Amp}+0.5 \mathrm{mM} \\
\mathrm{AgNO}_{3}\end{array}$ & $\begin{array}{c}\text { Amp }+1.0 \mathrm{mM} \\
\mathrm{AgNO}_{3}\end{array}$ & $\begin{array}{c}\mathrm{Amp}+1.5 \mathrm{mM} \\
\mathrm{AgNO}_{3}\end{array}$ & $\begin{array}{c}\mathrm{Amp}+2.0 \mathrm{mM} \\
\mathrm{AgNO}_{3}\end{array}$ \\
\hline S. aureaus & $15 \pm 0.56$ & $17 \pm 1.25$ & $18 \pm 0.98$ & $19 \pm 0.12$ & $19 \pm 0.98$ \\
\hline \multicolumn{6}{|c|}{ Vancomycin $(10 \mu \mathrm{g} / \mathrm{disc})$} \\
\hline & Van (zone in mm) & $\begin{array}{c}\text { Van }+0.5 \mathrm{mM} \\
\mathrm{AgNO}_{3}\end{array}$ & $\begin{array}{c}\text { Van }+1.0 \mathrm{mM} \\
\mathrm{AgNO}_{3}\end{array}$ & $\begin{array}{c}\text { Van }+1.5 \mathrm{mM} \\
\mathrm{AgNO}_{3}\end{array}$ & $\begin{array}{c}\text { Van+2.0 mM } \\
\mathrm{AgNO}_{3}\end{array}$ \\
\hline S. aureaus & $13 \pm 0.24$ & $17 \pm 0.76$ & $15 \pm 1.54$ & $14 \pm 2.05$ & $18 \pm 1.30$ \\
\hline \multicolumn{6}{|c|}{ Bacitracin (8 units/disc) } \\
\hline & Bac (zone in mm) & $\begin{array}{c}\mathrm{Bac}+0.5 \mathrm{mM} \\
\mathrm{AgNO}_{3} \\
\end{array}$ & $\begin{array}{c}\mathrm{Bac}+1.0 \mathrm{mM} \\
\mathrm{AgNO}_{3} \\
\end{array}$ & $\begin{array}{c}\mathrm{Bac}+1.5 \mathrm{mM} \\
\mathrm{AgNO}_{3}\end{array}$ & $\begin{array}{c}\mathrm{Bac}+2.0 \mathrm{mM} \\
\mathrm{AgNO}_{3}\end{array}$ \\
\hline S. aureaus & $19 \pm 0.85$ & $20 \pm 0.17$ & $21 \pm 1.12$ & $21 \pm 0.76$ & $22 \pm 0.89$ \\
\hline
\end{tabular}

All experiments were performed in triplicates and the results are expressed as mean \pm S.D. $(n=3)$

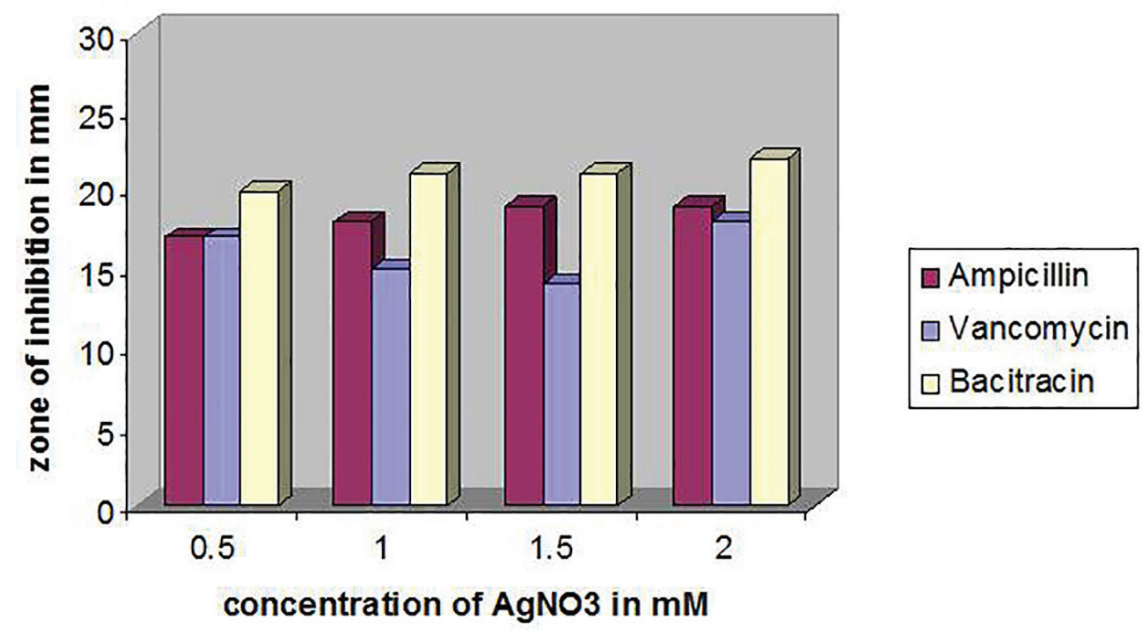

FIGURE 6 - Zone of inhibition (in $\mathrm{mm}$ ) for different antibiotics (ampicillin, vancomycin and bacitracin) at different concentrations of $\mathrm{AgNO}_{3}(0.5,1,1.5$ and $2 \mathrm{mM})$. 


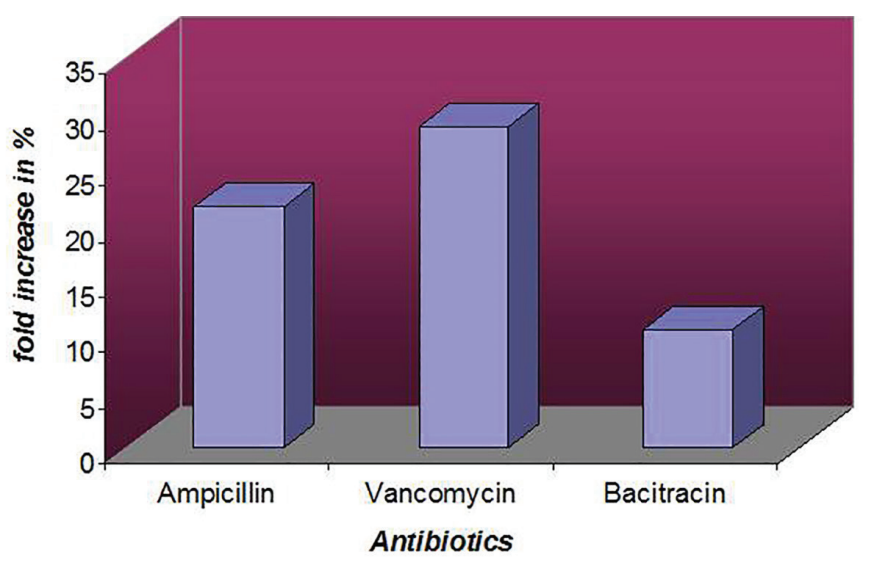

FIGURE 7 - Percentage fold increase in antibacterial activity of antibiotics and antibiotics with AgNPs.

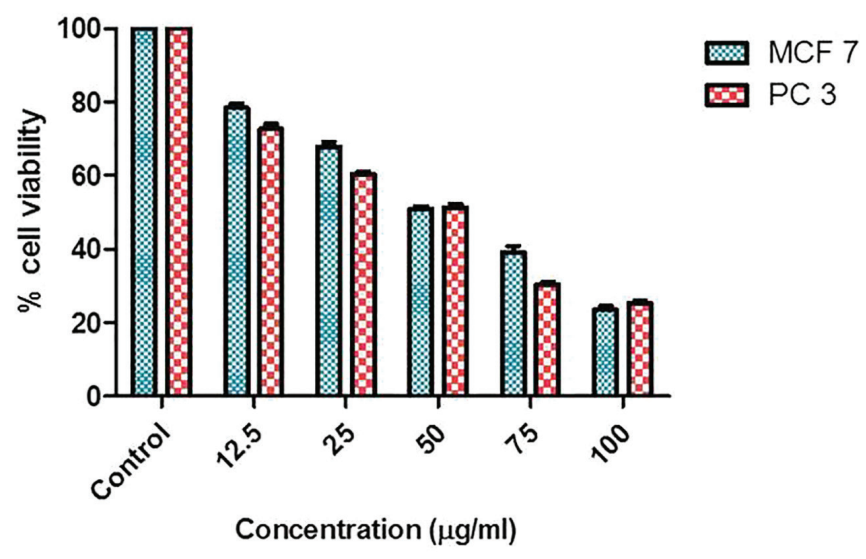

FIGURE 8 - In vitro cytotoxicity assay of different concentrations of AgNPs against MCF 7 and PC 3 cells, expressed in percentage viable cells.

incubation time increases, the intensity of color in flask containing cell filtrate and $\mathrm{AgNO}_{3}$ also increased. As shown in previous literatures, these observations indicate that the enzyme responsible for the formation of silver nanoparticles is being released into the cell filtrate (Das et al., 2014; Kushwaha et al., 2015). Therefore, on addition of the substrate, the enzyme brings about the reduction of silver ions to silver nanoparticles, thereby achieving extracellular synthesis of nanoparticles. The production of silver nanoparticles in the medium was monitored through UV-visible spectroscopy.

UV-visible spectroscopy is one of the conformational techniques used to determine the formation of silver nanoparticles. Through the literatures it has been observed that an increase in the absorbance at $420-430 \mathrm{~nm}$ indicates the formation of silver nanoparticles due to the surface plasmon resonance of the metal (Basavaraja et al., 2008). In our study, the UV recordings were analysed and the formation of silver nanoparticles were determined by a peak at the same wavelength. The silver nanoparticles produced were optimized by varying the substrate concentrations from $0.5-2.0 \mathrm{mM}$. From this study it was inferred that the maximum production of nanoparticles was observed at a concentration of $2.0 \mathrm{mM}$. Figure 3 indicates the gradual increase in the intensity of colour from pale yellow to dark brown. The morphology of the synthesized nanoparticles was studied by AFM. AFM studies were carried out for samples with varying substrate concentrations. It was concluded that as the substrate concentration, i.e., $\mathrm{AgNO}_{3}$ concentration increased, the size of the particles also increased which were observed to range from $79-107 \mathrm{~nm}$ for the substrate concentrations from 0.5-2.0 mM. The results obtained from this study showed that the fungus, Scedosporium is capable of producing silver nanoparticles of different sizes depending upon the concentration of silver nitrate. One of the applications of silver nanoparticles is that, these have been widely used as an effective antimicrobial agent against a wide range of pathogens.

The antimicrobial potential of silver nanoparticles synthesized from endophytic fungi was studied against $S$. aureus. The results obtained showed an inhibition zone of $14.0 \mathrm{~mm}$, which was reported to show a potent antimicrobial activity (Netala et al., 2015). A similar study was carried out to determine the antimicrobial property of silver nanoparticles synthesized from Trichoderma viride. This study also showed an excellent antimicrobial activity of silver nanoparticles synthesized from the fungi (Elgorban et al., 2016). Our study was carried out to determine the antimicrobial activity of the silver nanoparticles synthesized. This was performed by using different standard antibiotics. The nanoparticles were used along with the antibiotics to determine the synergistic effects of AgNps and the antibiotics and were tested against a Gram positive bacterium. Promising results were obtained where the nanoparticles showed activity against the test organism. Maximum activity was observed when the nanoparticles were used along with the antibiotic, Bacitracin, showing its synergistic effect. The activity was tested for nanoparticles at different substrate concentrations against the same test organism and was observed that as the concentration of substrate increased, the antimicrobial activity also increased in case of nanoparticles used with antibiotics bacitracin and ampicillin. Therefore, from our study it was concluded that as the size of the nanoparticles increased from $0.5-2.0 \mathrm{mM}$, the antimicrobial activity also was observed to increase against the test organism, also showing a high synergistic effect with bacitracin and ampicillin. Nanoparticles with bacitracin showed to have maximum activity at all concentrations of the substrate. 
AgNPs, along with their potent antibacterial activity are also known to possess anticancer activity. In our study, the anticancer activity of AgNPs against breast cancer cells (MCF 7) and prostate cancer cells (PC 3) were studied. It was observed that the AgNPs synthesized from Sceidosporium sps. isolated from soil showed good anticancer activity. As the concentration of AgNPs increased, a decrease in the cell viability was observed. This showed that AgNPs along with its antimicrobial nature could also be used as a potent anticancer agent for targeting breast and prostate cancers. Therefore, through this study, it could be said that extracellular synthesis of silver nanoparticles from Scedosporium was simple, ecofriendly, proving excellent antimicrobial and anticancer agents.

\section{ACKNOWLEDGEMENT}

The authors would like to acknowledge VIT University for providing all the requirements for carrying out the work.

\section{REFERENCES}

Ahmad A, Mukherjee P, Senapati S, Mandal D, Khan MI, Kumar R, et al. Extracellular biosynthesis of silver nanoparticle using the fungus Fusarium oxysporum. Colloid Surface B. 2003;28(1):313-8.

Basavaraja S, Balaji SD, Lagashetty A, Rajasab AH, Venkataraman A. Extracellular biosynthesis of silver nanoparticles using the fungus Fusarium semitectum. Mater Res Bull. 2008;43(5):1164-70.

Bhainsa KC, D'Souza SF. Extracellular biosynthesis of silver nanoparticles using the fungus Aspergillus fumigatus. Colloid Surface B. 2006;47(2):160-4.

Chen JC, Lin ZH, Ma XX. Evidence of the production of silver nitrate via pretreatment of Phoma sp.3.2883 with silver nitrate. Lett Appl Microbiol. 2003;37(2):105-8.

Das VL, Thomas R, Vargese RT, Soniya EV, Matthew J, Radhakrishnan EK. Extracellular synthesis of silver nanoparticles by the Bacillus strain CS 11 isolated from industrialized area. 3 Biotech. 2014;4(2):121-126.

Dias MA, Lacerda IC, Pimentel PF, de Castro HF, Rosa CA. Removal of heavy metals by an Aspergillus terreus strain immobilized in polyurethane matrix. Lett Appl Microbiol. 2002;34(1):46-50.
Duran N, Marcato PD, Alves OL, De Souza GIH, Esposito E. Mechanistic aspects of biosynthesis of silver nanoparticles by several Fusarium oxysporum strains. J Nanobiotechnol. 2005;3(8):1-7.

Elgorban AM, Al-Rahmah AN, Sayed SR, Hirad A, Mostafa AA, Bahkali AH. Antimicrobial activity and green synthesis of silver nanoparticles using Trichoderma viride. Biotechnol Biotec EQ. 2016;30(2):299-304.

Fayaz AM, Balaji K, Girilal M, Yadav R, Kalaichelvan PT, Venketesan R. Biogenic synthesis of silver nanoparticles and their synergistic effects with antibiotics: a study against grampositive and gram-negative bacteria. Nanomed Nanotechnol Biol Med. 2010;6(1):103-9.

Gajbhiye M, Kesharwani J, Ingel A, Gade A, Rai M. Fungus mediated synthesis of silver nanoparticles and their activity against pathogenic fungi in combination with fluconazole. Nanomed Nanotechnol Biol Med. 2009;5(4):382-6.

Kalimuthu K, Babu RS, Venkataraman D, Bilal M, Gurunathan S. Biosynthesis of silver nanocrystals by Bacillus licheniformis. Colloid Surface B. 2008;65(1):150-3.

Keat CL, Aziz A, Eid AM, Elmarzugi NA. Biosynthesis of nanoparticles and silver nanoparticles. Biores Bioproc. 2015;2:47.

Kholoud MM, El-Nour A, Eftaiha A, Al-Warthan A, Ammar RAA. Synthesis and applications of silver nanoparticles. Arab J Chem. 2010;3:135-40.

Kushwaha A, Singh VK, Bhartariya J, Singh P, Yasmeen K. Isolation and identification of $\mathrm{E}$. coli bacteria for the synthesis of silver nanoparticles: Characterization of the particles and study of antibacterial activity. Eur J Exp Biol. 2015;5(1):65-70.

Mohammadian A, Shojaosadati SA, Rezaee MH. Fusarium oxysporium mediates photogeneration of silver nanoparticles. Sci Iranica. 2007;14(4):323-6.

Netala VR, Bobbu P, Ghosh SB, Tartte V. Endophytic fungal assisted synthesis of silver nanoparticles, characterization, and antimicrobial activity. Asian J Pharma Clinical Res. 2015;8(3):113-6.

Sadowski Z, Maliszewska IH, Grochowalska B, Polowczyk I, Kozlecki T. Synthesis of silver nanoparticles using microorganisms. Mater Sci. 2008;26(2):419-24. 
Saminathan K. Biosynthesis of silver nanoparticles from dental caries causing fungi Candida albicans. Int J Curr Microbiol Appl Sci. 2015;4(3):1084-91.

Siddiqi KS, Husen A. Fabrication of metal nanoparticles from fungi and metal salts: scope and application. Nano Res Lett. 2016;11(1):98.

Sunderamoorthi C, Kalaivani M, Mathews DM, Palanisamy S, Kalaiselvan V, Rajasekaran A. Biosynthesis of silver nanoparticles from Appergillus niger and evaluation of its wound healing activity in experimental rat model. Int $\mathrm{J}$ PharmTech Res. 2009;1(4):1523-9.

Vahabi K, Mansoori GA, Karimi S. Biosynthesis of silver nanoparticles from fungus Trichoderma reesei. Insciences J. 2011;1(1):65-79.
Varshney R, Mishra AN, Bhadauria S, Gaur MS. A novel microbial route to synthesize silver nanoparticles using the fungus Hormoconis resinae. Digest J Nanoscience Biostructure. 2009;4(2):349-55.

Vigneshwaran N, Ashtaputre NM, Varadarajan PV, Nachane RP, Paralikar KM, Balasubramanya RH. Biological synthesis of silver nanoparticles using the fungi Aspergillus flavus. Mater Lett. 2011;61(6):1413-8.

Received for publication on $22^{\text {nd }}$ December 2016 Accepted for publication on $03^{\text {rd }}$ August 2018 